\title{
Article
}

\section{Forging 'Soft' Accountability in Unlikely Settings: A Conceptual Analysis of Mutual Accountability in the Context of South- South Cooperation}

Taekyoon, Kim and Sojin, Lim

Available at http://clok.uclan.ac.uk/17577/

Taekyoon, Kim and Sojin, Lim ORCID: 0000-0003-1395-7672 (2017) Forging 'Soft' Accountability in Unlikely Settings: A Conceptual Analysis of Mutual Accountability in the Context of South-South Cooperation. Global Governance, 23 (2). pp. 183-203. ISSN 1075-2846

It is advisable to refer to the publisher's version if you intend to cite from the work. http://dx.doi.org/10.5555/1075-2846.23.2.183?code=Irpi-site

For more information about UCLan's research in this area go to http://www.uclan.ac.uk/researchgroups/ and search for <name of research Group>.

For information about Research generally at UCLan please go to http://www.uclan.ac.uk/research/

All outputs in CLoK are protected by Intellectual Property Rights law, including Copyright law. Copyright, IPR and Moral Rights for the works on this site are retained by the individual authors and/or other copyright owners. Terms and conditions for use of this material are defined in the policies page. 


\title{
FORGING 'SOFT' ACCOUNTABILITY IN UNLIKELY SETTINGS: \\ A CONCEPTUAL ANALYSIS OF MUTUAL ACCOUNTABILITY IN THE CONTEXT OF SOUTH-SOUTH COOPERATION
}

\begin{abstract}
This study sets out to introduce the concept of 'soft' accountability as a new approach to understand mutual accountability (MA) in unlikely settings of development cooperation through South-South Cooperation (SSC). In doing so, this study analyzes three defining components of accountability (responsibility, answerability and enforceability), and identifies the actors and modalities of MA in four different situations of SSC mechanisms. The main finding in this conceptual analysis contains establishing an institutional and sustainable development platform for SSC MA by not only reflecting the distinctive nature of SSC but also focusing on responsibility first in order to reduce buck-passing among actors and to sustain its continuous management.
\end{abstract}

\begin{abstract}
Keywords
Mutual Accountability, South-South Cooperation, Soft Accountability, Sustainable Development, Responsibility, Answerability, Enforceability
\end{abstract}

Word Number: 8,119 


\section{Introduction: The 'Orphan' Pillar in 'Unlikely' Settings}

International development efforts have been long cherished as the global North's one-sided humanitarian intervention into the global South's poverty and disease issues. Since the Paris Declaration of 2005, however, recent requests for mutual accountability for the global partnership echo not only donor-driven demands for holding partner countries to account but also partner countries' strategic concerns regarding the transparent and receptive management of donors' development policies. ${ }^{1}$ In addition, the emerging importance of development cooperation among developing countries, which is often described as South-South cooperation (SSC), has increasingly received warm consideration from international aid agencies due to its complementarity with the traditional utility of North-South cooperation. The core value of mutual accountability, therefore, is re-examined as a crosscutting essence for both North-South cooperation and SSC, particularly in light of the contemporary changing development landscape.

Although the commitments of the Millennium Development Goals (MDGs) still remain unfulfilled, the international aid community is now heading towards a new Post-2015 development era. The world economic crisis has eroded the debt sustainability of developing countries, trade negotiations have been stalemated with the waning of the World Trade Organization (WTO) system and fragmented into multiple free trade agreements, and the equal access to affordable medicines and technology has become patchy. Traditional donors of the Organisation for Economic Cooperation and Development (OECD) Development Assistance Committee (DAC) are facing serious economic downturn and this has resulted in an ensuing budget cutback of official development assistance (ODA). Against such an adverse backdrop, it is a prerequisite to accelerate the progress of enabling environments which invites emerging SSC providers into a new global partnership framework beyond the outdated SSC. ${ }^{2}$ Another key part of building such a global partnership stems from accountability mechanisms which make development partners more mutually accountable to each other, thereby reinforcing mutual trust and positive incentives to further participate in development partnership. ${ }^{3}$

The growing centrality of SSC is a result of its complementary role in sustaining the current global architecture of international development. ${ }^{4}$ In particular, the 2008 Accra High Level Forum III formally endorsed the contributory function of SSC for aid effectiveness, and the 2011 Busan High Level Forum IV re-emphasized the vitality of SSC as one of the key success points in its Global Partnership for Effective Development Cooperation (hereinafter, the Busan Global Partnership).UN Secretary-General Ban Ki-Moon's message for the UN Day for SSC in 2013 openly confirmed the significance of SSC by underlining its contributions to common development challenges through sharing best practices, funding pilot projects with local knowledge, providing the capital to scale up successful projects and supplying regional public goods with appropriate technologies. SSC partners turn to each other for lessons on innovative policies and schemes to address and share their own successful experiences. Indeed, more proper solutions are available across the global South, which, if adequately harnessed, make meaningful contributions at both the regional and global level.

The issue of accountability, akin to SSC, has obtained relatively recent attention from the international aid community. At the 2005 High Level Forum II, mutual accountability (MA) was spotlighted as one of the key principles for the Paris Declaration, while the Busan Global Partnership reinforced MA as one of the four major principles of the Busan Outcome Document. In addition, Mr. Ban's synthesis report - 'The Road to Dignity by 2030' - to the UN General Assembly in December 2014 galvanized the transparency and evaluative contributions of MA to the processes of Post-2015 development agendas. It is a cliché to state that MA promotes an equal partnership between programme countries and aid providers and should be a key means of ensuring compliance with MDGs' commitments, the Busan Global Partnership, and the Sustainable Development Goals (SDGs) beyond 2015. However, there is 
no internationalized general consensus on the definition of MA and its associated mechanisms to put MA into practice. Requesting accountability generates double jeopardy for donors in terms of not only meeting the transparent and accountable use of national levies for aid but also holding recipient governments accountable for their commitments. Still, there is a serious lack of scholarly attempts to discuss how to render SSC accountable.

In fact, linking MA with SSC is a complex task for the following two reasons. Firstly, the notion of MA per se is slippery with its conceptual loopholes lacking sophisticated components consisting of MA. Translating the idea of MA into international aid practices has not been easy, particularly in terms of its practical scope - accountability to whom and for what? Unlike the other four principles of the Paris Declaration, measuring MA has not been cemented as a mature method for enhancing aid effectiveness. It is in this regard that MA has been cynically treated as the 'orphan pillar' of the Paris Declaration. ${ }^{5}$ Secondly, MA's translation by SSC leads to the politicization problem: public accountability is converted into a political agenda calling into question how Southern partners hold the others to account while all SSC partners work together for solidarity-based common goals. ${ }^{6}$ Embedding mutual accountability into the barren soil of SSC often remains as an inherently contested, politically misleading, and practically ineffectual process. Given that SSC is constituted on the virtue of mutual benefit and the recognition of reciprocity among partner countries, the request of MA, by all accounts, becomes a sensitive issue, which drives them into the arena of conflict over who is accountable to whom, thereby exploring the rugged landscapes of power and voice in accountability politics. $^{\text {? }}$

In this regard, this study is undertaken to fill in an explanatory vacuum at the intersection of SSC and MA by aiming to provide a conceptual/theoretical overview of how accountability fits into the domain of SSC. Its focal points involve a scholarly scrutiny of the social construction between the Western concept of accountability and the local realities of programme countries. Accountability is viewed as a normative condition for the effective implementation of aid programmes, and the point of analysis is focused on institutional transfers of accountability by examining how the Western norm is accepted and institutionalized in the local settings of programme countries. As the global South has been keen on the issue of dependencies upon aid packages from the North, imposing MA mechanisms without considering national variances of programme countries results in weighing down counterparts in the South. In view of that, we propose 'soft' accountability as an alternative concept of MA, suitable for SSC's unlikely settings. In practice, all partners need to redouble their efforts to harness the wealth of knowledge, expertise and development thinking of the global South within the frame of MA. The fundamental goal of accountability mechanisms involves behavioural changes for development partners and the reduction of buck-passing. The appropriate graft of MA onto SSC becomes a critical platform for undergirding a positive linkage between the significance of accountability and the rise of the global South, but how to marry MA with SSC has not yet begun to be discussed.

In identifying soft accountability for SSC, this study proceeds in four steps. Firstly, it starts by reconsidering MA in the developmental context and reviewing the historical evolution of SSC as an analytical backdrop for the premise that MA remains opaque in order to illustrate its effective functions within SSC. Secondly, it seeks to translate MA in the context of SSC by not only classifying the three components (responsibility, answerability, and enforceability) but also making possible scenarios of MA in different settings of SSC. Thirdly, it seeks to assess ways of forging MA for SSC by addressing the feasibility of soft accountability. Lastly, the conclusion proposes the key components of soft accountability by emphasizing the interconnectedness of local MA and international MA for SSC.

\section{The Stunted Evolution of Mutual Accountability}


Normally, accountability mechanisms in the domestic terrain require three institutional components to hold political elites to account:1) democratic voting or appointing mechanisms; 2) evaluation processes; and 3) withdrawal of political support, along with shaming and physical sanctions if their performances are poor. ${ }^{8}$ However, in most areas of global governance, different forms of accountability co-exist in an incomplete form. Critically, the lack of centralized public authorities hampers global stakeholders from calling upon MA to be operated in a democratic fashion. When it comes to mutually accountable mechanisms, the purview of account-holders and duty-bearers becomes much more complicated and the exact location of responsibility becomes blurred.

Aid giving has increasingly been under scrutiny with increasing demands for accountable results since the 2005 Paris Declaration. The Paris Declaration stipulates that MA can be enhanced by jointly assessing mutual progress in implementing agreed commitments on aid effectiveness through existing country level mechanisms. However, the result of the MA principle was far from the target, even though a progress was made to some extent. By the end of 2010, only 38 per cent of developing countries had introduced mutual review process. Among these, only 32 per cent of sub-Saharan African countries had established MA mechanisms, while about 60 per cent of Asia and the Pacific countries had implemented MA mechanisms.

Subsequently, the Accra Agenda for Action reaffirmed the crucial need for MA along with transparency by presenting it as 'essential elements for development results." However, the Paris MA indicator remained the same in the Accra Agenda for Action without further improvement and the Busan Global Partnership also failed to change or advance the existing approach to MA. Indeed, development partners fell behind the MA target of the Paris Declaration, due to the lack of clear-cut conceptualization. Despite the growing consensus on the significance of MA, the definitional contestation of accountability retarded its semantic and institutional consolidation. Although the Paris and Accra agreements have gradually broadened understanding of MA and have slowly changed aid stakeholders' behaviour, MA still appears to be an emerging agenda and it needs to be further developed in order to achieve concrete understanding amongst aid stakeholders.

Another reason for disappointing results of the MA principle could be due to there being no single over-arching authority to monitor behaviours and govern corrections for stakeholders. In particular, donors lack willingness to accept the enforcement mechanism for poor performance. At the core of MA is how development partners mutually hold themselves to account through the availability of information, performance monitoring, and adequate incentives for compliance. Under the absence of a globalized central authority, the MA principles are unable to be fully adapted amongst development partners at the country level, even though a handful of evidence lies in anecdotal records from aid workers in countries.

The political rhetoric of MA, nevertheless, has been evolving in two positive directions. Firstly, the UN Development Group has enlarged the concept of 'data revolution' by coining the term 'accountability revolution' in order to establish data-enabled national, regional and international frameworks for monitoring and accountability of development delivery. ${ }^{10}$ The urge for moving frontiers from data revolution to accountability revolution reflects not only the rationale that transparency is not enough to be accountable for development results, but also the UN Secretary-General's emphasis on the significance of robust accountability mechanisms for all stakeholders in achieving SDGs beyond 2015. ${ }^{11}$ Secondly, more engagement from the bottom level in public management, such as citizens' participation, can be also a useful driver for achieving accountability revolution in the Post-2015 development era. ${ }^{12}$ Such a mobilization of civic engagement aims to prevent political elites from enjoying permanent power. This civic intervention in political affairs makes political leaders of aid-receiving countries sensitive to the demands of MA. 


\section{South-South Cooperation at the Crossroads}

We now turn briefly to review the historical evolution of SSC from the Bandung Conference to its contemporary stage. The birth of SSC can be found in the Bandung Conference in 1955 as an effort to promote non-aligned cooperation across the global South. In 1978, the UN Conference on Technical Cooperation among Developing Countries took initiative for the official strategic framework for SSC as the result of the Buenos Aires Plan of Action. ${ }^{13}$ Meanwhile, the G77, created in 1964, has been acting as a formal cooperation forum for the global South under the UN context, and has continuously adopted milestones of international efforts, such as the Charter of Algiers (1967), the Buenos Aires Plan of Action (1978), the Caracas Declaration (1989), the First South Summit in Havana (2000), the first SSC conference on science and technology in Dubai (2002) and the Second Summit in Doha (2005). Besides the G77, the G33 in the WTO and the G24 in the IMF have also played roles in driving SSC in international cooperation. ${ }^{14}$

The original definition of SSC was built upon political, economic and social exchanges, including trade, investment and technology among Southern partners, the private sector and civil society organizations (CSOs). However, the Accra High Level Forum III redefined SSC within the development cooperation regime by focusing on South-South peer learning and knowledge sharing as a way of solving 'common' development challenges. ${ }^{15}$ This change reflects the 'horizontal partnerships' of SSC spirit articulated with equity, trust, mutual benefit and flexibility. Accordingly, SSC includes concessional loans and grants, including technical cooperation, provided for development purposes.

However, SSC has faced challenges, such as a lack of appropriate monitoring and evaluation, managing quality data, and improving transparency. ${ }^{16}$ As such, these limitations prompted SSC to learn from North-South cooperation to stimulate transparency and MA. Both the Accra Agenda for Action and the Busan Global Partnership clearly encouraged all development partners, including SSC actors, to adapt and enrich the aid effectiveness principles of the Paris Declaration in order to enhance the complementarity with the traditional North-South cooperation. Notwithstanding, the Busan Global Partnership's 10 indicators and four shared principles remained as a voluntary code of conduct, rather than compulsory clauses. It is also worthwhile to note that some SSC providers still consider the Busan Global Partnership as a strong push from traditional donors, thereby preferring more neutral mechanisms, such as the G20. ${ }^{17}$

In spite of the dearth of robust MA mechanisms for SSC, the UN and international aid communities, as in the 2003 Marrakech Declaration on SSC, recognized that SSC is not an option but an imperative to complement North-South cooperation in achieving the MDGs. ${ }^{18}$ SSC is about the force of solidarity and mutual benefit, with which international aid communities can overcome even the biggest challenges in the wake of the financial crisis and economic downturns in traditional donor states. Meanwhile, UN agencies agreed on the importance of tracking, monitoring and evaluating and mainstreaming activities on SSC in the UN Development Cooperation Forum. Such a consensus on the need for accountability mechanisms in SSC with even an embryonic form was balanced out by another consensus that MA for SSC must be demand-driven and implemented in accordance with national priorities. Also, donor agencies generally seem to agree on the introduction of SSC at the regional and sub-regional levels through regional coordination arrangements. ${ }^{19}$ By contrast, the Southern partner countries appear to have big concerns about the risk of MA in the sense of the North's initiative and dominance in shaping normative ideas of MA and its risks in abusing power rather than regulating power-holders. Thus, the point of analysis focuses on an uncomfortable mix of SSC's positive contributions to aid relations and its negative combination with MA. 


\section{Translating Mutual Accountability into South-South Cooperation}

OECD-DAC donors' formulation of MA has a particular set of mechanisms for themselves, despite still lacking clear systemic implementation mechanisms. Without modifications, they should not simply be translated and applied as 'the universal model' for middle/low-income countries engaged in SSC. The experience of accountability is not only highly diverse and complex but also becomes easily politicized in terms of the North-South dichotomy. SSC engages MA in ways that takes account of the articulated approaches of SSC: strengthening capacities for self-development, implementing principles of country ownership, equality and mutual benefit, and sharing development experience amongst SSC partners.

Customizing MA for SSC is a necessary condition for forging accountability mechanisms properly for its unlikely settings. Two processes are required for this customization. First, some distinctive characteristics of SSC are taken into consideration: conventionally weak domestic demands for holding governmental implementers accountable to their commitments; and long historical legacies of SSC based upon trust building and mutual benefits, in accordance with non-intervention of sovereign issues. The calibre of MA for SSC should be re-crystallized in the context of intergovernmental relations of the global South, rather than in the domestic dimensions of full-blown democracies. SSC and its aid relations are difficult to value on a comparable basis across countries anchored in North-South cooperation. It is thus critical to see whether cultural relativity impacts the exportation of accountability and results in successful acceptance, hybrid accountability or voluntary accountability. ${ }^{20}$

Nevertheless, there are some lessons from DAC donor practices which SSC partners may find relevant as they develop their own path of MA. At the national level, accountability is a political issue between the state and civil society in the sense that it is how 'the governed' hold 'the governors' to account. ${ }^{21}$ Problems of capture and bias indicate that both formal and informal systems of accountability unfairly exclude vulnerable groups and reinforce inequality. On the other hand, 'accountability politics' can be applied to the principal-agent relationship between aid-giving countries and programme countries. Obviously, accountable delivery of development cooperation is critical to improving its quality and effectiveness in achieving better development results. It is a central problem in politics that SSC actors must seriously take into consideration - poorly designed programmes can undermine accountability. Focusing on accountability in the domain of SSC, thus, is controversial, because it concerns the nature of the political settlement.

In this sense, it is critical to articulate how the existing conceptualization of MA can be reshaped for the unusual context of SSC. The generic term of MA holds the notion that 'programme partners and all other development cooperation actors are called to be accountable for the effectiveness of development cooperation, but they all need to make accountability more mutual, by making providers more accountable to programme country governments, and providers and programme country governments more accountable to intended beneficiaries of development cooperation and taxpayers in provider countries. ${ }^{22}$ Since this term provides definitional contents but remains still too broad to be relevantly modified to SSC, MA needs to be more sophisticatedly re-conceptualized by the partition of its three conceptual components responsibility, answerability, and enforceability - for the sake of more rigorous application. ${ }^{23}$

Firstly, responsibility is counted as an essential component of accountability, in that those in positions of authority clearly define duties and performance standards, enabling their agencies to be reviewed transparently and objectively. Accountability makes it possible to delineate the respective responsibilities of different actors in the development processes. Clear identification of who is responsible for which commitments at the initial stage of aid programmes contributes to avoiding confusion on the issue of who is the partner who can hold the other partners to account for particular activities throughout the implementation and 
evaluation process of aid programmes. Varieties of methods can be employed to clarify where responsibilities lie among programme partners involved: policy dialogues, MOU, due diligence programmes, safeguards, and so on. ${ }^{24}$

Secondly, the dimension of answerability requires that public officials and institutions provide reasoned justifications for their decisions to those they affect, particularly the public at large. In the context of development, the power balance between individuals and state institutions, or between providers of aid and the programme partners who use it, is often an asymmetrical. $^{25}$ Enhancing transparencies for informational sharing transforms this asymmetry by recasting the relationship in terms of duty bearers and rights holders, empowering individuals (partner countries) to control the behaviour of public institutions (the other partners) as a matter of entitlement, and promoting the quality of monitoring and evaluation (M\&E) and peer review via symmetrically shared information and data openness. Accordingly, the concept of accountability is necessarily put on a more comprehensive terrain than transparency, because answerability is rather equivalent with transparency in practical terms.

Thirdly, enforceability requires public institutions to operate mechanisms that monitor the degree to which public officials and institutions comply with established standards, impose sanctions on officials who do not comply, and ensure that appropriate corrective and remedial action is taken when required. Enforcing accountability is not only concerned with penalties, but is about ensuring fair and systematic mechanisms are in place to assess compliance by partner countries with agreed standards of responsibility. In this sense, the introduction of enforcement mechanisms is regarded as the last resort for one partner to call on other partner countries to be accountable through either inspection mechanisms, for instance the Inspection Panel of the World Bank, or the rigorous oversight of progress, such as the Compliance Review mechanism of the Asian Development Bank. ${ }^{26}$

All in all, the MA prototype requires all three elements to be organically interconnected with each other: agreed standards to assign the responsibilities; transparent transfers of information; and established corrective actions against misbehaviours of public agencies. The Principal-Agent theory rephrases this by stating that principals must be able to evaluate the actions of the agencies and to sanction them if their performance is poor, for instance by removing them from their positions of authority. ${ }^{27}$ Thus, effective accountability requires mechanisms for steady and reliable information and communication between stakeholders as well as mechanisms for imposing penalties when required. ${ }^{28}$

However, either international aid agencies or traditional donors, which meet these three conditions of MA, are very rare. Indeed, it is not an easy task to satisfy all of them simultaneously by trying to be more open and attentive to serious complaints arising during programme implementation, adapting changing needs throughout the programme cycle, and complying with inspection results of punishments. Particularly, the enforceability factor is the most taxing component to the specific case of North-South cooperation, mainly because traditional donors are reluctant to adopt enforcement mechanisms that may hold back their strategic manoeuvres. What is worse, SSC partners have a strong tendency to perceive all three components as a kind of threat or structured shackles by which traditional donors rule the behaviour of partner countries. ${ }^{29}$ Therefore, the three components of MA need to be winnowed out by characterizing the horizontality of South-South development cooperation.

\section{Modalities of Accountability Mechanisms in South-South Cooperation}

Another way of translating MA for SSC is to conceive possible cases which can occur in the different combinations of related factors to both SSC and MA. As Richard Mulgan aptly asserts, accountability for collective action gives rise to a recurring problem of whether accountability should be concentrated or diffused. ${ }^{30}$ According to the number of actors involved and the profile of development cooperation programmes, the practical modalities of MA and the degree 
of buck-passing (or accountability sharing) will be envisaged in varying ways. As Figure 1 illustrates, the dimension that is used for a conceptual typology of the MA-SSC nexus is two-fold: 1) the number of actors (binary vs. plural); and 2) modalities of SSC (technical cooperation vs. infrastructure projects). Then, the two-by-two matrix demonstrates four possible scenarios of SSC by crosschecking the number of actors and modalities of SSC.

The main form of development cooperation in SSC, regardless of the number of actors, consists of technical cooperation aimed at promoting mutual trust, self-sustained cooperation, and solidarity, rather than being infrastructure-centred. ${ }^{31}$ The main reason for this observation results from the inherent nature of technical cooperation whose programmes cover a wide range of low cost schemes, such as technology transfers, knowledge sharing and exchange, co-research projects, training programmes, workshops and conferences, and human networking. Technical cooperation takes advantages of operational flexibilities and low cost in terms of time management, the number of participants, and the density of legal constraints. Therefore, enhancing the capacity of partner countries is taken into account as a critical instrument for consolidating MA among SSC countries. SSC actors, on the other hand, are prone to shirk financial responsibilities for high-cost investments when it comes to infrastructure projects requiring the rigid debt relationship with programme partners.

Likewise, the actor-based approach to modalities of SSC provides another interesting point: without the institutional setting for MA, the presence of two actors only, no matter whether they opt for technical cooperation or infrastructure, would create lower possibilities of buck-passing, whereas multiple stakeholders tend to pass the buck to other partners due to endogenous difficulties in clarifying where responsibilities lie evidently among the multiple number of actors. ${ }^{32}$ This phenomenon is quite a natural process, from the perspective of the rational-choice institutionalism, because the plural number of actors, under the absence of accountability mechanisms, fails to overcome the perverse incentives of actors that prevent collective-action problems from being solved. ${ }^{33}$

\section{Figure 1. Actors and Modalities of South-South Cooperation}

\begin{tabular}{|c|c|c|}
\hline & Binary & Plural \\
\hline $\begin{array}{c}\text { Technical } \\
\text { Cooperation }\end{array}$ & Trust Building & Ad hoc Buck-Passing \\
\hline $\begin{array}{l}\text { Infrastructure- } \\
\text { centred }\end{array}$ & Strategic Alliance & Routinized Buck-Passing \\
\hline
\end{tabular}

In the first category of the actor-modality matrix in which only two actors intend to carry out a set of technical cooperation, the relational pattern of actors' behaviour would boil down to the form of 'trust building.' The purpose of technical cooperation, when the two SSC actors 
pursue it in ad hoc meetings for training courses for instance, does not require high cost inputs of financial resources but intends to enrich mutual benefits by exchanging official staff and CSOs. The type of trust building, thus, does not have to call upon the two actors to be strictly accountable for their performance, mainly because bucks each actor needs to take responsible for are not heavy or even unclear. This pattern seems to be taken normally by the initial stage of consolidating mutual trust between two SSC actors. For example, the case of 'Bangladeshi-Korea BRAD Community Development' represents a classic scenario of trust building of the binary technical cooperation mechanism. In this case, both parties shared tacit accountability under the clear division of mandates: while the government of Bangladesh was responsible for deputing senior officials to the site, the Korean government was responsible for dispatching experts from Korea to the site. Both parties are expected to increase mutual benefits and synergy effects in the development process at the local level, by exchanging human resources. ${ }^{34}$ Such a binary technical cooperation-based project, due to its nature of low cost inputs and mutual trust, does not require a meticulous set of MA.

In the second category where multiple partners operate technical cooperation, all actors involved tend to find a way of passing the buck to each other, on an ad hoc basis, rather than in a routinized fashion. ${ }^{35}$ For instance, in the case of 'China-International Poverty Reduction Centre in China (IPRCC) as a Platform for SSC', not only relevant ministries of China, but also several international institutions and bilateral donor agencies are engaged in IPRCC's main task of organizing exchange of poverty reduction knowledge and experience and providing training and consultancy services. Likewise, the case of 'Thailand-Cambodia-Laos-Myanmar-Vietnam Human Resources Development' confirms the second category of the MA-SSC nexus, in the sense that the Thailand International Cooperation Agency undertook technical cooperation-based projects for bridging development gaps between Thailand and Cambodia, Laos, Myanmar and Vietnam, based on each country's comparative advantages with the recognition of the needs of partnership building to grow and prosper together through a multi-sectoral approach. These two cases demonstrate that accountability deficits are less seriously taken than those in infrastructure-based projects, even though multiple-stakeholders are ready to pass their bucks to other actors if the projects turn out to be failures. With a low level of mutual accountability in the mechanism, any centralized authorities, which can regulate all partners, have not been established yet. Without the mechanisms of MA, the innate attribute of multiplicity would prompt all actors to have perverse incentives of eschewing their own bucks, due to the absence of centralized authorities to regulate wilful behaviours of actors. Nevertheless, the density of buck-passing in technical cooperation will be no greater than in the case of infrastructure/investment, in that technical cooperation per se does not require a large scale of development financing, takes the off-the-cuff operational patterns in many cases, and hardly creates a high value of bucks. The introduction of MA to this categorization would be the best solution to not only institutionalize and consolidate the long-term sustainability of SSC, but also minimize the probability of collective action problems.

The third category composed of two actors and infrastructure-based cooperation would result in the relational feature of 'strategic alliance' under the lack of accountability mechanisms. Given the fact that there are only two players and that the SSC provider decides to assist a high-cost investment project at the expense of its national assets, it is highly plausible to assume that the SSC provider possesses strategic concerns and geopolitical proximity to support the targeted partner with the aim of holding the partner to be in favour of its strategic position. Instead, the provider needs to embark upon accountability mechanisms, at least to ask the partner country to submit periodic reports, to systematize information sharing, and to fulfil the conditions of coordination meetings and M\&E. We collect three cases from the data pool, all of which confirm Egypt's strategic moves on to its neighbouring fragile countries such as South Sudan and Uganda. 
The fourth pattern is found clearly in situations such as multiple-actors' engagement in infrastructure or turnkey projects, in which the plural number of SSC actors are able to play dual roles as providers or recipients by investing in a commonly targeted sector at either the regional or specific country level. No accountability mechanisms would end in the worst scenario of governance within which each actor's perverse incentive tends to override the urgency of common targets, thereby multiplying buck-passing, which cannot easily be tracked down. Indeed, it is not a plain process to delineate sharply not only who should be accountable but also to what degree the multiple stakeholders should be accountable for what. ${ }^{36}$ In consequence, this mode is most negatively conceived of being achievable in practice, which is confirmed by just one case that we found from the case collection of the TT-SSC (see Table1).

In a nutshell, there are two observations affecting commonly all four categorizations. Firstly, the multiple-actor-based modality of SSC shows more inclination to not only pass the buck to others when partners face the request for responsibility for the result of aid projects than bilateral-development modality. Secondly, the infrastructure/investment-based approach requiring high-cost inputs is equipped with much tighter mechanisms for accountability than technical cooperation-based cooperation. It is thus fair to argue that the combination of multiple actors and technical cooperation would be the most popular pattern that SSC actors prefer to take due to diluted requests for accountability as well as the tacit tolerance of buck-passing. Nevertheless, this multi- technical cooperation modality will be forced to call all participants to account if it seeks to sustain its long-term development. Sustainable and accountable development presupposes the greater participation of aid recipients and other related partners. Such a shift implies a concomitant decline in aid supplier's authority over its own aid packages, but a greater responsibility on the side of the recipient. Therefore, the call for accountability mechanisms being rooted into the soil of SSC is a dead-end that the global South cannot avoid if it wants to make SSC more sustainable.

Table 1. Selected Cases of the Four Categories

\begin{tabular}{|c|c|}
\hline $\begin{array}{l}\text { Trust Building } \\
\text { (Bi-Technical } \\
\text { Cooperation) }\end{array}$ & $\begin{array}{l}\text { - Bangladeshi-Korea BRAD Community Development } \\
\text { - China-India Exchanging Development Experiences } \\
\text { - Laos-Vietnam Exchanging on Local Administration } \\
\text { - Reform } \\
\text { - Vietnam-Nepal Exchanging on Development Strategies }\end{array}$ \\
\hline $\begin{array}{l}\text { Ad Hoc Buck-passing } \\
\text { (Multi-Technical } \\
\text { Cooperation) }\end{array}$ & $\begin{array}{l}\text { - } \text { Barefoot College - Boosting Rural Solar Energy } \\
\text { - } \text { China-IPRCC as a Platform for SSC } \\
\text { - } \text { Cuba-Africa Promoting Integrated Health Services } \\
\text { - IBSA-Guinea Bissau Boosting Food Self-Sufficiency } \\
\text { - India-Pan-African E-Network for Medical Services and } \\
\text { - Human Services } \\
\text { - ThPAD Promoting E-Schools in Africa } \\
\text { Humandiand-Cambodia-Laos-Myanmar-Vietnam ACMECS } \\
\text { Humarces Development }\end{array}$ \\
\hline $\begin{array}{l}\text { Strategic Alliance } \\
\text { (Bi-Infra) }\end{array}$ & $\begin{array}{l}\text { - Egypt-South Sudan Generating Electricity in South Sudan } \\
\text { - Egypt-South Sudan Establishing Two Family Medical } \\
\text { Units in South Sudan } \\
\text { - Egypt-Uganda Aquatic Weed Control in Uganda }\end{array}$ \\
\hline
\end{tabular}


Routinized Buck-Passing (Multi-Infra)
- NEPAD Investing in Agriculture and Food Security in Africa

Sources: $\underline{\text { www.southsouthcases.info. }}$

\section{Forging Accountability Mechanisms in South-South Cooperation}

The next task for forging MA for SSC is to discuss which component of MA is the first-order condition for the successful management of operating SSC under the assumption that all three components are not satisfied and how MA can be realistically tailored to the distinctive assets of SSC and local contexts of South-South partners. Not taking for granted the existing Western conceptualization of MA, SSC needs to develop its own path of accountability mechanisms to prevent the other partners from abusing power and resources and enhance trust building and knowledge sharing for mutual benefit. It is thus important to note that mainstreaming MA into SSC implies the systematic search of its distinctive trajectory by means of the reflexive review of the Western concept and practices of MA.

Figure 2. Spectrum of Mutual Accountability Mechanisms

Early initial stages

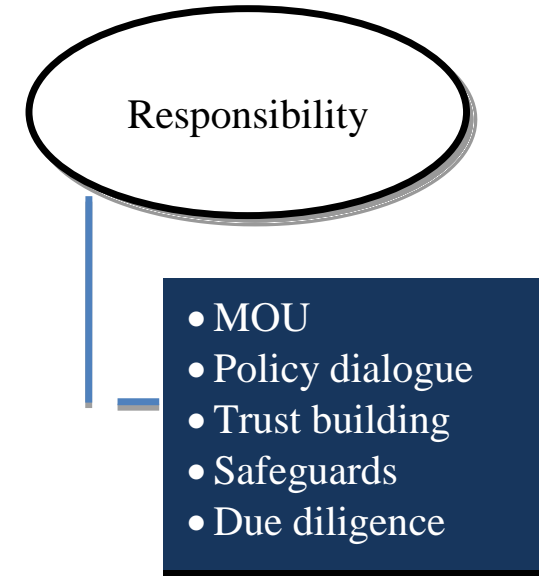

Final stages/last resorts

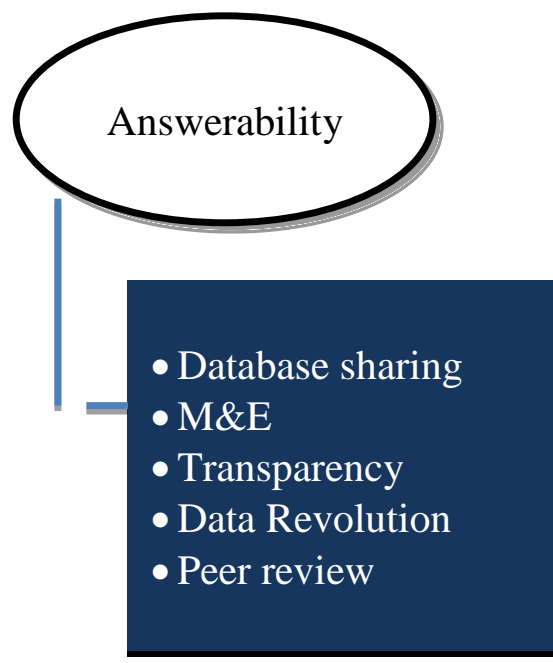

Most of all, it is necessary to review how the three components of MA can be customized to the context of SSC. On the spectrum of time spans indicating the degree of maturity in implementing development cooperation programmes (see Figure 2), each element of MA responsibility, answerability and enforcement - is respectively positioned at different points of time. Responsibility is undertaken as the major value and mechanism for loosened patterns of development cooperation at the initial stage. Answerability denotes more matured 
accountability systems than responsibility in the sense that all actors at this stage mutually hold each other to be accountable through mutual assessment, M\&E, transparent information sharing and peer review. Enforcement is referred as to the last resort of MA in which actors are able to bring legal claims to the inspection panel or compliance review panels for the purpose of ex post resettlement processes. However, all three components are not always mutually exclusive.

It is recognizable that the current level of institutional maturity in cases of SSC retards its MA mechanism from functioning in tandem with answerability and enforceability. Starting from responsibility clarifying duty-bearer vis-à-vis rights-holder, SSC is able to identify its precise space, time and conditions under which MA can be institutionally consolidated even in a partial form. Ultimately, to mainstream MA for SSC involves the task of how to soften accountability mechanisms, rather than that of how to accommodate itself to the international standards of MA as a whole. Considering that the political elites of developing countries may lack understanding of accountability and have lower credibility of institutionalizing accountability mechanisms, we are not able to drive them into copying the Western model of MA without adjustments for their own cultural and historical variations. ${ }^{37}$

Hence, accountability mechanisms need to be institutionally set up and locally consolidated on the demand-driven basis of SSC partner countries. 'Going local' matters with regards to better governance of accountability in order to manage a variety of tasks amidst conflicting pressures and new expectations for the local contexts of SSC partners. ${ }^{38}$ Developing countries, particularly in crisis and transition situations, will face strong challenges at the national-level MA, much more severe than traditional donors in financial crises. Strong national-level mutual accountability mechanisms have a major quantifiable impact on changing SSC countries' behaviour in the way they manage and deliver development cooperation. Therefore, the strong encouragement that all SSC countries proactively participate in the formation of national-level MA mechanisms first is a silver-bullet for mainstreaming MA in the unlikely context of SSC.

In so doing, SSC actors keep on holding the dimension of responsibility as the essential foundation; if excessively speedy commitments are carried out in this process, for instance adopting enforcement mechanisms, they fail to sustain institutional reforms for translating MA into their own contexts. In this sense, aid effectiveness depends upon aid programmes that strengthen, not undermine, domestic accountability, even though domestic accountability mechanisms are affected and complicated by multiple global factors, mainly external aid donors. A minimal approach to MA, embedded in the domestic milieu of SSC partners, is worth considering as an institutional safeguard to prevent perverse incentives from being pursued even at an initial stage of accountability mechanisms in unlikely settings of SSC. On top of national MA, international-level accountability can be further coordinated and developed by reflecting and orchestrating locally-driven frameworks to monitor the quality and results of development cooperation, including specific annual performance targets for individual partner countries, aligned to national development priorities. ${ }^{39}$

\section{Concluding Remarks: In Search of Soft Accountability}

The accountability mechanism is at the centre of democratic governance. According to Francis Fukuyama, the concrete development of political accountability is the de facto sweeping account of why some countries in the world failed to survive and some countries continued to prevail. ${ }^{40}$ Daron Acemoglu and James Robinson, in a similar vein, argue that economic success will be sustained when the government becomes accountable and responsive to citizens and the great mass of people in the country. ${ }^{41}$ In the domain of global governance, their scholarly accounts are not easily applied, owing to the absence of centralized enforcement authorities that regulate and coordinate varieties of national contexts in a single frame. Moreover, SSC represents a separate zone from the traditional architecture of aid effectiveness 
and global governance. Accordingly, the making of MA for SSC requires new alternative approaches to repair rifts between the global North and the global South. This is the very reason why we need seek the 'soft accountability' apart from the traditional Western models.

MA for SSC is required to launch a domestic accountability mechanism in order to make it more transparent and sustainable. It should be a deliberate outgrowth of reflecting distinctive conditions of developing countries involved in SSC, rather than importing MA's Western models without modifications. In the longer term, it also needs to be aligned and harmonized with international or regional standardizations of MA. However, there is always a serious loophole in connecting national MA with international MA: who is going to take the lead of this linkage? Strong global accountability frameworks call for the need for political leadership or centralized authorities in implementing coordinated outcomes from accountability dialogues to promote behavioural changes at the global level and the decentralizing process to fit national priorities as well.

Such an institutional effort to set in motion MA at the domestic level of SSC countries should concentrate on the initial domain of responsibility first, rather than the full package of accountability. The rash demand for answerability and enforceability easily comes to bring about the politicization of MA among SSC countries, mainly because they are sensitive enough to external interventions into national affairs and sovereign issues. The slack profile of technical cooperation-centred projects among SSC partners also dilutes the sense of strong monitoring systems and accountability review mechanisms. The request for enforcement is too early to be taken into consideration by partner countries, as they have no genuine interest in how to hold each other to account mutually through tight legal policies.

Any credible MA frame for SSC, therefore, is expected to revisit the existing universal standardization of accountability mechanisms, which culminates in how to make an alternative definition of 'soft' accountability. Soft accountability shares Gunnar Myrdal's assumptions on 'soft state', with specific reference to a general societal indiscipline which manifest itself by deficiencies in accountability mechanisms, particularly enforcement, a widespread perverse incentive by SSC partners, and its collusion with the Western view of accountability. ${ }^{42}$ Having said that, soft accountability is referred to as a flexible re-conceptualization of accountability, designed to enhance its adaptability to SSC partners, on the basis of their own distinctions of contextual environments, as well as varying degrees of capabilities in introducing accountability mechanisms to coordinate and regulate the behaviours of SSC partners. Among the three components of MA discussed above, responsibility would be a stepping stone of soft accountability in the context of SSC, but soft accountability is supposed to contain the next stages of MA, such as answerability and enforceability in accordance with due course of time and due process of institutional maturity.

Some descriptions of MA for SSC are further undertaken to consolidate the concept of soft accountability. The following four essences for these conditions are summarized and suggested on the basis of what we have discussed hitherto: 1) soft accountability should be voluntary based and self-disciplinary; 2) soft accountability should be based upon demand-driven accountability mechanisms; 3) an international MA platform is required to coordinate and customize the different contexts of SSC partners; and 4) soft accountability should adopt the discourses of global partnership with the rectification and modification by which SSC partners are able to translate them into their own standards.

In search of soft accountability, it is important to remember that the overemphasis of accountability is always counterproductive in terms of its negative impacts on the efficiency of aid projects. ${ }^{43}$ Introducing MA with no serious consideration of local conditions in partner countries fails to achieve its original goals of holding all participants to account; rather, it is more likely to undermine efficiency in exchange for enhancing accountability in an abused fashion. Accordingly, an incremental institutionalization of MA through the softening process 
of how accountability mechanisms are realistically adapted to local culture and values would be the effective way of reducing the probability of abusing MA and reconciling the trade-off between accountability and efficiency.

\section{Notes}

1 The Paris High-Level Forum II in 2005 reached the Paris Declaration with five principles: ownership, alignment, harmonization, managing with results and mutual accountability.

2 Manmohan Agarwal, "South-South Economic Cooperation for a Better Future," in Sachin Chaturvedi, Thomas Fues, and Elizabeth Sidiropoulos, eds., Development Cooperation and Emerging Powers: New Partners or Old Patterns? (London: Zed Books, 2012), pp. 37-66.

3 Julia Steets, Accountability in Public Policy Partnerships (Basingstoke: Palgrave, 2010); Jennifer Brinkerhoff, Partnership for International Development: Rhetoric or Results? (Boulder: Lynne Rienner Publishers, 2002).

${ }^{4}$ UNDP, 2013 Human Development Report: The Rise of the South: Human Progress in a Diverse World (New York: UNDP, 2013).

${ }^{5}$ AusAid, "Mutual Accountability: 'Orphan' Principle of the Paris Declaration," ODE Issues Note (Canberra: Office of Development Effectiveness, 2008).

${ }^{6}$ David Held and Mathias Koenig-Archibugi, eds., Global Governance and Public Accountability (Oxford: Blackwell, 2005); Jonathan Fox, "The Uncertain Relationship between Transparency and Accountability," Development in Practice 17, no. 4-5 (2007): 663-671.

${ }^{7}$ Ruth Grant and Robert Keohane, "Accountability and Abuses of Power in World Politics," American Political Science Review 99, no. 1 (2005): 29-43.

8 Robert Keohane, "Global Governance and Democratic Accountability," in David Held and Mathias

Koenig-Archibugi, eds., Taming Globalization: Frontiers of Governance (Cambridge: Polity, 2002), pp. 130-159.

${ }^{9}$ Liesbet Steer and Cecilie Wathne, Mutual Accountability at the Country Level: Emerging Good Practice Paper (London: ODI, 2009).

${ }^{10} \mathrm{UN}$, Draft Agenda for Dialogue: Data and Accountability for the Post-2015 Development Framework (New York: UN, 2014).

${ }^{11} \mathrm{UN}$, “A Life of Dignity for All: Accelerating Progress towards the Millennium Development Goals and Advancing the United Nations Development Agenda beyond 2015," Report of the Secretary-General (New York: UN, 2013).

${ }^{12}$ IDEA, Democratic Accountability in Service Delivery: A Practical Guide to Identify Improvements through Assessment (Stockholm: IDEA, 2013).

${ }^{13}$ In 2003, the Technical Cooperation among Developing Countries was renamed as the Special Unit for South-South Cooperation (SU-SSC).

${ }^{14}$ San Bilal, What is the Rise of South-South relations About? Development, Not Aid (Brussels: European Centre for Development Policy Management, 2012).

15 Ajay Tejasvi, “South-South Capacity Development: The Way to Grow?" Capacity Development Briefs No. 20. (Washington, D.C.: World Bank, 2007).

16 Bilal, p. 5.

${ }^{17}$ Taekyoon Kim, “Towards a Transformative Global Partnership for a Post-2015 Development Era,” Issue Brief for the 2015 UNDCF High-Level Symposium in Incheon, Republic of Korea (http://www.un.org/en/ecosoc/newfunct/pdf15/dcfrok_global_partnership issue brief.pdf).

${ }^{18}$ UN. "State of South-South Cooperation," Report of Secretary-General (New York: UN, 2003).

19 Anne-Marie Goetz and Rob Jenkins, Reinventing Accountability: Making Democracy Work for Human Development (Basingstoke: Palgrave Macmillan, 2005).

${ }^{20}$ Diana Leat, "Voluntary Organizations and Accountability: Theory and Practice," in Helmut Anheier and Wolfgang Seibel, eds., The Third Sector: Comparative Studies of Nonprofit Organizations (Berlin: Walter de Gruyter, 1990), pp. 141-154.

21 Richard Mulgan, Holding Power to Account: Accountability in Modern Democracies (Basingstoke: Palgrave Macmillan, 2003).

${ }^{22} \mathrm{UNDCF}$, Mutual Accountability for Development Cooperation Results: Where Next? (New York: UNECOSOC, 2012), p. 2.

${ }^{23}$ UN, Who Will Be Accountable? Human Rights and the Post-2015 Development Agenda (New York: UN, 2013).

${ }^{24}$ In case of safeguards, ADB, alongside the World Bank, sets up three major safeguard categories: (i) environmental impacts, (ii) involuntary resettlement, and (iii) the rights of indigenous peoples. See Asian 
Development Bank, Accountability Mechanism Policy 2012 (Manila: Asian Development Bank, 2013).

25 Peter Newell and Shaula Bellour, Mapping Accountability: Origins, Contexts and Implications for Development (Brighton: Institute of Development Studies, 2002).

${ }^{26}$ The Inspection Panel is an independent accountability mechanism of the World Bank, established in 1993. The Panel provides a forum for people who believe that they may be adversely affected by Bank-financed operations to bring their concerns to the highest decision-making levels of the World Bank. The Panel determines whether the Bank is complying with its own policies and procedures, which are designed to ensure that Bank-financed operations avoid harm to people and the environment. Likewise, ADB's Compliance Review Panel was established as one of components of its institutional reforms to strengthen accountability. Alongside the Compliance Review Panel, the introduction of Accountability Mechanism policy became effective in May 2012 and has resulted in clearer and closer collaboration between the functions of problem solving and compliance review.

${ }^{27}$ Gary Miller, "The Political Evolution of Principal-Agent Models," Annual Review of Political Science 8 (2005): 203-225.

28 Robert Keohane and Joseph Nye, "Redefining Accountability for Global Governance," in Miles Kahler and David Lake, eds., Governance in a Global Economy: Political Authority in Transition (Princeton: Princeton University Press, 2000), pp. 386-411.

${ }^{29}$ Such a negative feedback to MA resulted from the field research that we undertook in January 2014 for focus group interviews with key decision-makers of development policies in Indonesia, Vietnam, Myanmar, and Cambodia.

${ }^{30}$ Mulgan, Holding Power to Account, p. 190.

31 We collected and analyzed all SSC cases, listed by the TT-SSC, and sorted them out in accordance with the two-by-two frame and its categories in the above (see figure 1). The full data can be reached at www.southsouthcases.info.

${ }^{32}$ Jürgen Rüland, "Southeast Asian Regionalism and Global Governance: "Multilateral Utility" or "Hedging Utility",' Contemporary Southeast Asia 31, no. 1 (2011): 83-112.

33 Clark Gibson, Krister Andersson, Elinor Ostrom and Sujai Shivakumar, The Samaritan's Dilemma: The Political Economy of Development Aid (New York: Oxford University Press, 2005); James Buchanan, "The Samaritan's Dilemma," in James Buchanan, ed., Freedom in Constitutional Contract: Perspectives of a Political Economist (College Station: Texas A\&M University Press, 1977), pp. 169-185.

${ }^{34}$ More detailed information can be found at http://www.southsouthcases.info/casosasia/caso 12.php.

35 L. David Brown, "Multiparty Social Action and Mutual Accountability," in Alnoor Ebrahim and Edward Weisband, eds., Global Accountabilities: Participation, Pluralism, and Public Ethics (Cambridge: Cambridge University Press, 2007), pp. 89-111.

36 Felix Zimmermann and Kimberly Smith, "More Actors, More Money, More Ideas for International Development Cooperation," Journal of International Development 23, no. 5 (2011): 722-738.

${ }^{37}$ Michael Bratton and Carolyn Logan, "Voters but Not Yet Citizens: Democratization and Development Aid," in Richard Joseph and Alexandra Gillies, eds., Smart Aid for African Development (Boulder: Lynne Rienner, 2009), pp. 181-206.

${ }^{38}$ Merilee Grindle, Going Local: Decentralization, Democratization, and the Promise of Good Governance (Princeton: Princeton University Press, 2007).

39 UNDCF, p. 3.

${ }^{40}$ Francis Fukuyama, Political Order and Political Decay: From the Industrial Revolution to the Globalization of Democracy (New York: FSG, 2014).

${ }^{41}$ Daron Acemoglu and James Robinson, Why Nations Fail: The Origins of Power, Prosperity, and Poverty (New York: Crown Business, 2012).

${ }^{42}$ Gunnar Myrdal, Asian Drama: An Inquiry into the Poverty of Nations (New York: Pantheon, 1968).

43 Robert Wade, “Accountability Gone Wrong: The World Bank, Non-governmental Organisations and the US Government in a Fight over China," New Political Economy 14, no. 1 (2009): 25-48; Taekyoon Kim, "Contradictions of Global Accountability: The World Bank, Development NGOs, and Global Social Governance," Journal of International and Area Studies 18, no. 2 (2011): 23-47. 